CDE

August, 2004

\title{
Analysis of Consumers' Perceptions of Buying Conditions for Houses
}

\author{
Pami Dua \\ Delhi School of Economics, Delhi, India \\ \& \\ Economic Cycle Research Institute, New York, U.S.A. \\ Email: dua@econdse.org
}

Working Paper No. 127

Centre for Development Economics

Department of Economics, Delhi School of Economics 


\title{
Analysis of Consumers' Perceptions of Buying Conditions for Houses
}

\section{Pami Dua}

\begin{abstract}
This paper examines the determinants of consumers' buying attitudes for houses. Data on buying attitudes are from responses to the Surveys of Consumer Attitudes conducted by the Survey Research Center, University of Michigan. The determinants considered include current and expected interest rates, current and expected real disposable income and house prices. The empirical estimates show that a long-run relationship exists between buying attitudes for houses and each of the above variables. Each of these determinants also Granger cause buying perceptions. Generalized impulse responses show that shocks to each of the above variables have a predictable and permanent impact on buying attitudes. Furthermore, generalized variance decompositions suggest that both current and expected interest rates explain a large proportion of the variation in consumers' perceptions towards buying houses. Since consumers' attitudes towards buying houses are likely to be translated into actual purchases, this study shows that in order of importance, interest rates - both current and future - have the maximum impact on decisions to purchase houses followed by expectations of real disposable income.
\end{abstract}

Keywords: Consumer Surveys, House Buying Attitudes, Cointegration, Generalized Variance Decompositions, Impulse Responses.

JEL Classification: C50, R20.

\section{Acknowledgements}

The author gratefully acknowledges support from the University of Connecticut's Center for Real Estate and Urban Economic Studies. The author is also grateful to the University of Michigan's Survey Research Center for making available responses to their Surveys of Consumer Attitudes and to Sumant Kumar Rai for diligent research assistance. 


\section{Introduction}

The housing sector is one of the largest sectors of the US economy and an important source of wealth building. It constitutes about $14 \%$ of GDP and comprises almost a third of total consumers' expenditure. Moreover about $70 \%$ of US households are homeowners. Changes in the housing sector are therefore expected to reverberate throughout the economy and are likely to impact other sectors of the economy.

This paper examines consumers' perceptions about buying conditions for houses. Consumers' attitudes towards buying houses are a barometer of conditions in the housing sector and have far-reaching effects on the economy. If consumers are optimistic about buying conditions for houses, they spend more on houses. This has repercussions throughout the economy since an increase in spending on houses generally increases the demand for a number of items ranging from building materials like lumber to finished goods such as household appliances and furniture. Likewise, if consumers are pessimistic about the buying climate for houses, they postpone buying a house and thus delay spending on these items.

It is therefore possible to define a set of economic variables that are likely to influence consumers' buying attitudes. For instance, the determinants of consumers' buying attitudes for houses are likely to be related to the factors that influence the demand for houses. These include variables such as employment and income levels that tend to produce real estate cycles. Higher employment and income are conducive to housing activity while lower levels are detrimental to real estate investment (Smith and Tesarek, 1991; Sternlieb and Hughes, 1977). Expectations about future economic conditions can also affect people's attitudes towards buying houses in a similar manner.

The mortgage interest rate is also expected to significantly influence an individual's decision to purchase a house. An increase in the mortgage rate or mortgage payment (including interest and principal) discourages people from buying a

\footnotetext{
${ }^{1}$ Two indicators of consumer attitudes, the Consumer Confidence Index of the Conference Board and the Consumer Sentiment Index of the Survey Research Center at the University of Michigan, are often used to measure consumers' perceptions of general economic conditions and their personal financial well being. The Consumer Sentiment Index also includes consumers' perceptions about buying major household items such as furniture, refrigerators, stoves, and television sets. Both indexes are tracked closely by the media and their properties have been examined in several studies including Garner (1991), Leeper (1992), Throop (1992), Fuhrer (1993), Carroll, Fuhrer, and Wilcox (1994), Matsusaka and Sbordone (1995) and Bram and Ludvigson (1998). Consumers' attitudes towards buying a house come from the same survey as the Consumer Sentiment Index.
} 
house and thus decreases the demand for houses. Significant effects of the interest rate on consumer expenditure are also expected via the effect on housing wealth especially when houses serve as a collateral (Muellbauer, 1992; Muellbauer and Murphy, 1997; Maclennan et al., 1998).

Housing prices can also influence people's incentive to invest in real estate both directly via the demand for houses and indirectly, through the effect on the inflation rate. For example, Feldstein (1992) shows that an increase in the general inflation rate (which is affected, amongst other factors, by the housing sector) decreases housing demand. Kearl (1979) indicates that inflation causes nominal housing payment to increase and thus decreases housing demand.

Several models have examined the effect of macroeconomic aggregates on the housing sector such as Kearl (1979), Follain (1981), Schwab (1983), Arnott (1987), Manchester (1987), Schwartz (1988), Smith et al. (1988), Harris (1989), Megbolugbe et al. (1991), Dua and Smyth (1995), Hanushek and Quigley (1982), Baffoe-Bonnie (1998), Chen and Patel (1998) and Ewing and Wang (2002).

In this paper we evaluate in a VAR framework, the relationship between consumers' buying attitudes towards houses and factors that are believed to influence them. The cointegrating relationship is estimated and granger-causality tests are conducted based on the corresponding error correction model. The generalized forecast error variance decomposition and the impulse responses are also examined. The relationship between buying attitudes and its determinants is estimated using monthly data from January 1984 through June 2003.

The paper is organized as follows. Section 2 describes the survey data on buying attitudes for houses. Section 3 describes the possible determinants of buying attitudes. Section 4 reports the econometric methodology, Section 5 reports the empirical estimates and Section 6 gives the conclusions.

\section{Survey Data on House Buying Attitudes}

Data on buying attitudes are from the responses of about 500 households per month to the Surveys of Consumer Attitudes conducted by the Survey Research Center, University of Michigan. The specific question on buying attitudes is:

"Generally speaking, do you think now is a good time or a bad time to buy a house?"

${ }^{2}$ Details of the survey are given in Curtin (1982). 
The responses are in three categories: the percentage responding "good time", the percentage responding "bad time", and the percentage saying "uncertain". From these responses, we construct an index of a good time to buy a house as follows:

(1) Buying Index $=$ good + uncertain $*$ good/(good+bad)]

where

good = the percentage of consumers responding good time;

bad = the percentage of consumers responding bad time;

and uncertain $=$ the percentage of consumers responding uncertain .

This index measures the percentage of respondents saying "good time" relative to the percentage of respondents saying "bad time". The uncertain responses are allocated to good and bad in the same proportion as those saying "good time" and "bad time". ${ }^{3}$ The buying index can lie between 0 and 100. An increase in the index indicates a rise in the percentage of consumers who are optimistic about purchasing a house.

Figure 1 plots the index from January 1981 through June 2003. The index varies from 16.5 percent in September 1981 to 92.71 percent in December 1998. After fluctuating between 16.5 percent and 27.4 percent during the period January 1981 to July 1982, the index increases to 69.5 percent in June 1983. These movements are consistent with the U.S. business cycle recession that lasted from July 1981 through November 1982. The index hits a new low of 51.1 percent in September 1984 before climbing to 88.7 percent in April 1986. The next local low is in October 1990 (53.2 percent) which corresponds to the business cycle recession that is dated from July 1990 through March 1991. After the dip in late 1990, the buying index rises to 89.6 percent in March 1994 and further to 92.7 percent in December 1998 after dropping temporarily to 67.7 percent in February 1995. It again drops to $64.9 \%$ in June 2000 and then gradually increases to $85.3 \%$ in May 2002.

During the 2001 recession (Mar 2001 to Nov 2001), the index varies between 73.4\% in April 2001 to $83.5 \%$ in November 2001. It goes up to $82.3 \%$ in June 2001, before going down to $75.8 \%$ in September 2001. These movements in the index are not entirely consistent with the recession during this time. Falling interest rates may have been the reason behind the observed healthy levels of the buying index even

\footnotetext{
${ }^{3}$ Variations of the index can be constructed as in Dua and Smyth (1995).
} 
as the economy was shrinking. In fact, without the support of the housing sector, the effect of the last recession may have been more severe.

While there is some tendency for buying attitudes to follow recessions, what other factors explain fluctuations in buying attitudes? Following the question on a good time or a bad time to buy a house, the respondents are asked a supplementary question as follows:

"Why do you say so?"

Selected reasons for saying "good time to buy" are: prices low, good buys available; prices won't come down; interest rate low; borrow in advance, rising rates; good investment; and times good, prosperity. Selected reasons for saying "bad time to buy" are: prices high; interest rates high, credit tight; can't afford to buy; and uncertain future.

From these responses, we can infer that buying attitudes depend on obvious housing sector variables such as house prices and the mortgage rate and variables pertaining to general economic conditions that measure "times good, prosperity". In the reasons stated, there is also reference to the "future" implying that future factors may affect house buying attitudes in addition to current variables. In the next section, we analyze these factors and describe ways to measure them.

\section{Determinants of Consumers' Buying Attitudes for Houses}

We divide the potential determinants of consumers' buying attitudes for homes into three categories as follows: housing sector factors such as house prices and the mortgage rate; factors that measure general economic conditions such as the real disposable income; and factors that measure future expected housing-related and general economic conditions. We discuss the measurement of each of these below.

\section{Housing sector variables}

Housing sector variables include house prices and the mortgage rate. House prices are measured by the median sales price of existing single-family homes and come from the National Association of Realtors. The mortgage rate is measured by the contract interest rate on single-family existing home purchases and is provided by the Federal Housing Finance Board. 


\section{Current economic conditions}

Current economic conditions are measured by the level of real disposable income. Real income is measured by disposable personal income in 2000 dollars, at seasonally adjusted annual rates. This is taken from the Federal Reserve Bank of St. Louis' database.

\section{Expected future housing and general economic conditions}

The responses to the supplementary question "Why do you say so?" suggest that the people surveyed take into account expectations of housing-related and general economic conditions to evaluate if the present time is a good time to buy a house. We derive expectations of these variables from the same survey. This ensures that the respondents to the question on buying conditions for houses are the same as the respondents to questions on expectations of economic conditions.

There are two questions asked in the Surveys of Consumer Attitudes that provide information on expected housing-related conditions and general economic conditions. These relate specifically to interest rates and real family income. However, quantified estimates of expectations of these variables are not available from this survey. We therefore construct indexes to measure these variables. ${ }^{4}$ These are discussed below.

\section{Index of interest rate expectations}

An index of expectations of interest rates is constructed from the responses to the following question asked in the Surveys of Consumer Attitudes:

"No one can say for sure, but what do you think will happen to interest rates for borrowing money during the next 12 months -- will they go up, stay the same, or go down?"

We calculate:

(2) Index of interest rate expectations $=u p+$ same $^{*}[u p /(u p+d o w n)]$

where

up = the percentage of consumers responding go up;

\footnotetext{
${ }^{4}$ It is possible to quantify the responses by using a procedure such as that developed in Carlson and Parkin (1975). However, such a procedure requires an assumption on the distribution of expectations among respondents and the imposition of unbiasedness. We prefer to use an index constructed from the raw data instead.
} 

down $=$ the percentage of consumers responding go down; and
and
same $=$ the percentage of consumers responding stay the same.

This index measures the percentage of respondents expecting interest rates to increase during the next 12 months relative to the percentage expecting interest rates to decrease. The "stay the same" responses are allocated to up and down in the same proportion as those saying "go up" and "go down".

\section{Index of real family income expectations}

An index of expectations of real family income is constructed from the following question:

"How about the next year or two -- do you expect that your (family) income will go up more than prices will go up, about the same, or less than prices will go up?"

These responses can be interpreted as: real income will go up, stay the same, or go down. From this, we calculate an index as follows:

(4) Index of real income expectations $=$ up + same*[up/(up+down)] where

$$
\begin{aligned}
\text { up }= & \text { the percentage of consumers responding income will go up } \\
& \text { more than prices will go up; } \\
\text { down = } & \text { the percentage of consumers responding income will go up } \\
& \text { less than prices will go up; }
\end{aligned}
$$

and $\quad$ same $=$ the percentage of consumers responding about the same.

This index measures the percentage of respondents expecting real income to go up in the next year or two relative to the percentage expecting real income to go down.

For purposes of estimation, all variables except those in percentages are measured in logs.

\section{Econometric Methodology}

This paper employs a VAR model that includes the house buying index, interest rates, real income, house prices and expectation indexes. Tests for nonstationarity are first conducted followed by tests for cointegration, estimation of a vector error 
correction model, tests for granger causality and generalized impulse responses and variance decompositions.

\section{Nonstationarity}

To test if the series are nonstationary or contain a unit root, we focus on the augmented Dickey-Fuller (ADF) test (1979, 1981), the Phillips-Perron (PP) test (1988) and the KPSS test proposed by Kwiatkowski et al. (1992).

We follow Doldado, Jenkinson and Sosvilla-Rivero's (1990) sequential procedure for the ADF test when the form of the data-generating process is unknown. Such a procedure is necessary since including the intercept and trend term reduces the degrees of freedom and the power of the test implying that we may conclude that a unit root is present when, in fact, this is not true. Further, additional regressors increase the absolute value of the critical value making it harder to reject the null hypothesis. On the other hand, inappropriately omitting the deterministic terms can cause the power of the test to go to zero (Campbell and Perron, 1991).

We also conduct the Phillips-Perron (1988) test for a unit root mainly because the Dickey-Fuller tests require that the error term be serially uncorrelated and homogeneous while the Phillips-Perron test is valid even if the disturbances are serially correlated and heterogeneous.

In both the ADF and the PP test, the unit root is the null hypothesis. A problem with classical hypothesis testing is that it ensures that the null hypothesis is not rejected unless there is strong evidence against it. Therefore these tests tend to have low power, that is, these tests will often indicate that a series contains a unit root. Kwiatkowski et al. (1992) therefore suggest that based on classical methods it may be useful to perform tests of the null hypothesis of stationarity in addition to tests of the null hypothesis of a unit root. Tests based on stationarity as the null can then be used for confirmatory analysis, that is, to confirm conclusions about unit roots. Of course, if tests with stationarity as the null as well as tests with unit root as the null both fail to reject the respective nulls or both reject the respective nulls, there is no confirmation of stationarity or nonstationarity.

Thus, three tests, ADF, PP and KPSS tests are used to test for the presence of a unit root. The KPSS test, with the null of stationarity, helps to resolve conflicts between the ADF and PP tests. If two of these three tests indicate nonstationarity for any series, we conclude that the series has a unit root. 


\section{Cointegration and Granger Causality}

The possibility of a cointegrating relationship between the variables is tested using the Johansen and Juselius $(1990,92)$ methodology. If the variables are indeed cointegrated, we can construct a vector error-correction model that captures both the short-run and long-run dynamics.

Consider the $\mathrm{p}$-dimensional vector autoregressive model with Gaussian errors:

$$
y_{t}=A_{1} y_{t-1}+\ldots . . .+A_{p} y_{t-p}+A_{0}+\varepsilon_{t}
$$

where $y_{t}$ is an $m \times 1$ vector of $\mathrm{I}(1)$ jointly determined variables. The Johansen test assumes that the variables in $y_{t}$ are I(1). For testing the hypothesis of cointegration the model is reformulated in the vector error-correction form

$$
\Delta y_{t}=-\Pi y_{t-1}+\sum_{i=1}^{p-1} \Gamma_{i} \Delta y_{t-i}+A_{0}+\varepsilon_{t}
$$

where, $\Pi=I_{m}-\sum_{i=1}^{p} A_{i}, \quad \Gamma_{i}=-\sum_{j=i+1}^{p} A_{j}, \quad i=1, \ldots \ldots, p-1$.

Here the rank of $\Pi$ is equal to the number of independent cointegrating vectors. If the vector $\mathrm{y}_{\mathrm{t}}$ is $\mathrm{I}(0)$, $\Pi$ will be a full rank $m \times m$ matrix. If the elements of vector $\mathrm{y}_{\mathrm{t}}$ are I(1) and cointegrated with rank $(\Pi)=\mathrm{r}$, then $\Pi=\alpha \beta^{\prime}$, where $\alpha$ and $\beta$ are $m \times r$ full column rank matrices and there are $r<m$ linear combinations of $\mathrm{y}_{\mathrm{t}}$. The model can easily be extended to include a vector of exogenous I(1) variables.

Under cointegration, the VECM can be represented as

$$
\Delta y_{t}=-\alpha \beta^{\prime} y_{t-1}+\sum_{i=1}^{p-1} \Gamma_{i} \Delta y_{t-i}+A_{0}+\varepsilon_{t}
$$

where $\alpha$ is the matrix of adjustment coefficients. If there are non-zero cointegrating vectors, then some of the elements of a must also be non zero to keep the elements of $y_{t}$ from diverging from equilibrium.

Johansen and Juselius $(1990,92)$ suggest the LR test based on the maximum eigenvalue $\left(\lambda_{\max }\right)$ and trace $\left(\lambda_{\text {trace }}\right)$ statistics to determine the number of the cointegrating vectors. Since $\lambda_{\max }$ test has a sharper alternative hypothesis as compared to $\lambda_{\text {trace }}$ test, it is used to select the number of cointegrating vectors.

If the presence of cointegration is established, the concept of Granger causality can also be tested in the VECM framework. For example, if two variables are cointegrated, i.e. they have a common stochastic trend, then causality in the 
Granger (temporal) sense must exist in at least one direction (Granger, 1986; 1988). Thus in a two variable vector error correction model, we say that the first variable does not Granger cause the second if the lags of the first variable and the error correction term are jointly not significantly different from zero. This is tested by a joint $\mathrm{F}$ or Wald $\chi^{2}$ test.

\section{Generalized Impulse Response Analysis}

Dynamic relationships among variables in VAR models can be analyzed using innovation accounting methods that include impulse response functions and variance decompositions. An impulse response function measures the time profile of the effect of shocks at a given point in time on the future values of variables of a dynamical system.

A major limitation of the conventional method advocated by $\operatorname{Sims}(1980,81)$ is that the impulse response analysis is sensitive to the ordering of variables in the VAR (see Lutkepohl, 1991). In this approach, the underlying shocks to the VAR model are orthogonalized using the Cholesky decomposition of the variance-covariance matrix of the errors, $\Sigma=E\left(\varepsilon_{t} \square_{t}^{\prime}\right)=P P^{\prime}$, where $P$ is a lower triangular matrix. Thus a new sequence of errors is created with the errors being orthogonal to each other, and contemporaneously uncorrelated with unit standard errors. Therefore the effect of a shock to any one of these orthogonalized errors is unambiguous because it is not correlated with the other orthogonalized errors.

Generalized impulse responses overcome the problem of dependence of the orthogonalized impulse responses on the ordering of the variables in the VAR. Koop et. al (1996) originally proposed the generalized impulse response functions (GIRF) for non-linear dynamical systems but this was further developed by Pesaran and Shin (1998) for linear multivariate models. An added advantage of the GIRF is that since no orthogonality assumption is imposed, it is possible to examine the initial impact of responses of each variable to shocks to any of the other variables.

The generalized impulse response analysis can be described in the following way ${ }^{6}$. Consider a VAR $(p)$ model:

$$
x_{t}=\sum_{i=1}^{p} \Phi_{i} x_{t-i}+\varepsilon_{t}, \quad t=1,2, \ldots, \mathrm{T} .
$$

\footnotetext{
${ }^{5}$ For a detailed discussion and proofs, see Pesaran and Pesaran (1997) and Pesaran and Shin (1998).
} 
where $x_{t}=\left(x_{1 t}, x_{2 t}, \ldots, x_{m t}\right)^{\prime}$ is an $m \times 1$ vector of jointly determined dependent variables and $\left\{\Phi_{i}, i=1,2, \ldots, p\right\}$ are $m \times m$ coefficient matrices.

If $x_{t}$ is covariance-stationary, the above model can be written as an infinite MA representation:

$$
x_{t}=\sum_{i=0}^{\infty} A_{i} \varepsilon_{t-i}, \quad t=1,2, \ldots, \mathrm{T} .
$$

where $m \times m$ coefficient matrices $A_{i}$ can be obtained using the following recursive relations:

$$
A_{i}=\Phi_{1} A_{i-1}+\Phi_{2} A_{i-2}+\ldots+\Phi_{p} A_{i-p}, \quad i=1,2, \ldots . .
$$

with $\mathbf{A}_{0}=\mathbf{I}_{\mathrm{m}}$ and $\mathbf{A}_{i}=\mathbf{O}$ for $i<0$.

Consider the effect of a hypothetical $m \times 1$ vector of shocks of size $\delta=\left(\delta_{1}\right.$, $\left.\ldots, \delta_{m}\right)^{\prime}$ hitting the economy at time $t$ compared with a base-line profile at time $t+n$, given the economy's history.

The generalized impulse response function of $x_{t}$ at horizon $n$, is given by:

$$
G I_{x}\left(n, \delta, \Omega_{t-1}\right)=E\left(x_{t+n} \mid \varepsilon_{t}=\delta, \Omega_{t-1}\right)-E\left(x_{t+n} \mid \Omega_{t-1}\right)
$$

where the history of the process up to period $t-1$ is known and denoted by the nondecreasing information set $\Omega_{\mathrm{t}}$.

Here the appropriate choice of hypothesized vector of shocks, $\delta$, is central to the properties of the impulse response function. By using Sims' (1980) Cholesky decomposition of $\Sigma\left(=E\left(\varepsilon_{t} \square \mathfrak{t}^{\prime}\right)\right)=\mathrm{PP}^{\prime}$, the $\mathrm{m} \times 1$ vector of the orthogonalized impulse response function of a unit shock to the jth equation on $\mathrm{x}_{\mathrm{t}+\mathrm{n}}$ is given by:

$$
\psi_{j}^{o}=A_{n} P e_{j}, \quad n=0,1,2, \ldots,
$$

where $\mathbf{e}_{\mathrm{j}}$ is an $\mathrm{m} \times 1$ vector with unity as its $j$ th element and zero elsewhere.

However, Pesaran and Shin (1998) suggest to shock only one element (say $j^{\text {th }}$ element), instead of shocking all elements of $\varepsilon_{t}$, and integrate out the effects of other shocks using an assumed or historically observed distribution of errors. Thus, now the generalized impulse response equation can be written as

$$
G I_{x}\left(n, \delta_{j}, \Omega_{t-1}\right)=E\left(x_{t+n} \mid \varepsilon_{j t}=\delta_{j}, \Omega_{t-1}\right)-E\left(x_{t+n} \mid \Omega_{t-1}\right)
$$

If the errors are correlated a shock to one error will be associated with changes in the other errors. Assuming that $\varepsilon_{\mathrm{t}}$ has a multivariate normal distribution, i.e., $\varepsilon_{t} \sim N(0, \Sigma)$, we have

$$
E\left(\varepsilon_{t} \mid \varepsilon_{j t}=\delta_{j}\right)=\left(\sigma_{1 j}, \sigma_{2 j}, \cdots, \sigma_{m j}\right)^{\prime} \sigma_{j j}^{-1} \delta_{j}=\Sigma e_{j} \sigma_{j j}^{-1} \delta_{j}
$$


This gives the predicted shock in each error given a shock to $\varepsilon_{\mathrm{jt}}$, based on the typical correlation observed historically between the errors. This is different from the case where the disturbances are orthogonal and the shock only changes the jth error as follows:

$$
E\left(\varepsilon_{t} \mid \varepsilon_{j t}=\delta_{j}\right)=\delta_{j} e_{j}
$$

By setting $\delta_{j}=\sqrt{\sigma_{j j}}$ in equation (7), i.e. measuring the shock by one standard deviation, the generalized impulse response function that measures the effect of a one standard error shock to the $j$ th equation at time $t$ on expected values of $x$ at time $t+n$ is given by

$$
\psi_{j}^{g}(n)=\sigma_{j j}^{-\frac{1}{2}} A_{n} \Sigma e_{j}, \quad \mathrm{n}=0,1,2, \ldots .
$$

These impulse responses can be uniquely estimated and take full account of the historical patterns of correlations observed amongst the different shocks. Unlike the orthogonalized impulse responses, these are invariant to the ordering of the variables in the VAR.

\section{Generalized Variance Decomposition Analysis}

The forecast error variance decompositions provide a breakdown of the variance of the $\mathrm{n}$-step ahead forecast errors of variable $\mathrm{i}$ which is accounted for by the innovations in variable $j$ in the VAR. As in the case of the orthogonalized impulse response functions, the orthogonalized forecast error variance decompositions are also not invariant to the ordering of the variables in the VAR. Thus, we use the generalized variance decomposition which considers the proportion of the N-step ahead forecast errors of $x_{t}$ which is explained by conditioning on the non-orthogonalized shocks, $\varepsilon_{i t}, \varepsilon_{i t+1}, \ldots, \varepsilon_{i t+N}$, but explicitly allows for the contemporaneous correlation between these shocks and the shocks to the other equations in the system.

Thus, while the orthogonalized variance decomposition (Lutkepohl, 1991) is given by,

$$
\theta_{i j}^{0}(n)=\frac{\sum_{l=0}^{n}\left(e_{i}^{\prime} A_{l} P e_{j}\right)^{2}}{\sum_{l=0}^{n}\left(e_{i}^{\prime} A_{l} \sum A_{l}^{\prime} e_{i}\right)} \quad i, j=1,2, \ldots, \mathrm{m} .
$$

the generalized variance decomposition is given by, 


$$
\theta_{i j}^{g}(n)=\frac{\sigma_{i i}^{-1} \sum_{l=0}^{n}\left(e_{i}^{\prime} A_{l} \sum e_{j}\right)^{2}}{\sum_{l=0}^{n}\left(e_{i}^{\prime} A_{l} \sum A_{l}^{\prime} e_{i}\right)} \quad i, j=1,2, \ldots, \mathrm{m}
$$

While by construction $\sum_{j=1}^{m} \theta_{i j}^{0}(n)=1$, due to the non-zero covariance between the non-orthogonalized shocks, $\sum_{j=1}^{m} \theta_{i j}^{g}(n) \neq 1$.

Pesaran and Shin (1998) have shown that the orthogonalized and the generalised impulse responses as well as forecast error variance decompositions coincide if $\Sigma$ is diagonal and for a non-diagonal error variance matrix they coincide only in the case of shocks to the first equation in the VAR. Thus to select between the orthogonalized and generalized analysis, we first test if $\Sigma$ is diagonal or not. The null hypothesis is:

$$
\mathbf{H}_{0}: \sigma_{i j}=0 \text {, for all } \forall i \neq j \text {. }
$$

where $\sigma_{i j}$ stands for the contemporaneous covariance between the shocks in the endogenous variables.

The Likelihood-ratio test statistic is given by

$$
\operatorname{LR}\left(\mathrm{H}_{0} \mid \mathrm{H}_{1}\right)=2\left(\mathrm{LL} u-L L_{R}\right)
$$

where $L L_{U}$ and $L L_{R}$ are the maximized values of the log-likelihood function under $\mathrm{H}_{1}$ (the unrestricted model) and under $\mathrm{H}_{0}$ (the restricted model), respectively. $L_{U}$ is the system log-likelihood and $L L_{R}$ is computed as the sum of the log-likelihood values from the individual equations. The LR test statistic follows a $\chi^{2}$ distribution with degrees of freedom equal to the number of endogenous variables.

\section{Generalized Impulse Response Analysis in a Cointegrated VAR Model}

The generalized impulse response analysis can be extended to a cointegrated VAR model. Consider the following Vector Error Correction Model (VECM) described by Pesaran and Shin (1998):

$$
\Delta x_{t}=-\Pi x_{t-1}+\sum_{i=1}^{p-1} \Gamma_{i} \Delta x_{t-i}+\varepsilon_{t}, \quad t=1,2, \ldots, \mathrm{T} .
$$

where $\Pi=I_{m}-\sum_{i=1}^{p} \Phi_{i}, \Gamma_{i}=-\sum_{j=i+1}^{p} \Phi_{j}$ for $i=1,2, \ldots, \mathrm{p}-1$, and $\Lambda$ is an $\mathrm{m} \times \mathrm{g}$ matrix of unknown coefficients. 
If $x_{t}$ is first-difference stationary, $\Delta \mathbf{x}_{t}$ can be written as the infinite moving average representation,

$$
\Delta x_{t}=\sum_{i=0}^{\infty} C_{i} \varepsilon_{t-i}, \quad t=1,2, \ldots, \mathrm{T} .
$$

The generalized impulse response function of $\mathbf{x}_{t+n}$ with respect to a shock in the jth equation is given by:

$$
\psi_{x, j}^{g}(n)=\sigma_{j j}^{-\frac{1}{2}} B_{n} \Sigma e_{j}, \quad n=0,1,2, \ldots
$$

where $B_{n}=\sum_{j=0}^{n} C_{j}$ is the cumulative effect matrix with $\mathbf{B}_{0}=\mathbf{C}_{0}=\mathbf{I}_{\mathrm{m}}$.

Similarly, the orthogonalized impulse response function of $\mathbf{x}_{\mathbf{t}}$ with respect to a variable-specific shock in the jh equation are given by

$$
\psi_{x, j}^{o}(n)=B_{n} P e_{j}, \quad n=0,1,2, \ldots
$$

Once again the two impulse response functions as well as the forecast error variance decompositions coincide if either the error variance-covariance matrix is diagonal or for a nondiagonal error variance-covariance matrix, if we shock the first equation in the VAR.

\section{Empirical Results}

We first test for nonstationarity of all the variables. The results of the three unit root tests are summarized in Table 1 that shows that all the variables can be treated as nonstationary. Testing for differences of each variable confirms that all the variables are integrated of order one.

We use Johansen's FIML technique to test for cointegration between Buying index, interest rates, real disposable personal income, house prices, and indexes of real income and the rate of interest. After ascertaining that the variables are integrated of the same order, we select the order of the VAR using the likelihood ratio test that suggests an optimal lag length of 4 .

The next step is the selection of the deterministic terms in VAR. Since most macroeconomic data exhibit a linear trend (and not quadratic trend) which can be captured by an intercept, therefore, we select an intercept in VAR but not trend.

The maximum eigenvalue test statistic strongly rejects the null hypothesis that there is no cointegration between the variables (i.e. $r=0$ ), but does not reject the hypothesis that there is one cointegrating relation between the variables (i.e. $r=1$ ) 
(Table 2). We find that all of the variables have the correct signs as suggested by the theoretical model. The cointegrating vector suggests that while the buying index is positively related to the real disposable income and index of real income expectations, it is negatively related to the interest rate, housing prices and the index of interest rate expectations. The signs are therefore economically plausible. The cointegrating equation ${ }^{6}$ is as follows:

\section{MODEL: $\mathrm{BI}=-13.77 i-0.15 i^{\mathrm{e}}+787.52 y+0.72 \mathrm{y}^{\mathrm{e}}-704.66 p$}

All the variables in the cointegrating vector are significant (Table 3). Using the vector error correction model, we test whether the variables individually Granger cause the Buying Index. For this, we test for the joint significance of the lagged variables of each variable along with the error correction term. The results reported in Table 4 indicate that the null hypothesis of no Granger causality is strongly rejected in all the cases, thus justifying their inclusion in the model.

An investigation of the dynamic interaction of various shocks in the post sample period is brought to the fore using the variance decomposition and the impulse response functions. Instead of the orthogonalized impulse responses, we use the generalized impulse responses and variance decompositions. The advantage of using the generalized impulse responses is that orthogonalized impulse response and variance decompositions depend on the ordering of the variables. If the shocks to the respective equations in VAR are contemporaneously correlated, then the orthogonalized and generalized impulse responses may be quite different. On the other hand, if shocks are not contemporaneously correlated, then the two types of impulse responses may not be that different and also orthogonalized impulse responses may not be sensitive to a re-ordering of the variables. Thus before proceeding further, we test the hypothesis that the off-diagonal elements in the covariance matrix equal zero. The LR test statistic is 65.7846 whereas the $95 \%$ critical value of the $\chi^{2}$ distribution with 6 degree of freedom is 12.5916 . Therefore, the null hypothesis that $\Sigma$ is diagonal is rejected. We therefore use the generalized impulse framework.

\footnotetext{
${ }^{6}$ Notation is as follows: $\mathrm{BI}$ is Buying Index, $i$ is current interest rate, ${ }^{e}$ is expected interest rate, $y$ is current real disposable income, $y^{\mathrm{e}}$ is expected real disposable income, and $p$ is current house prices.
} 


\section{Generalized variance decompositions and impulse response analysis}

Variance decompositions give the proportion of the h-periods-ahead forecast error variance of a variable that can be attributed to another variable. These therefore measure the proportion of the forecast error variance in the index for buying conditions for houses that can be explained by shocks given to its determinants. Results in Table 5 provide variance decompositions for a 24-month time horizon.

The table shows that at a forecast horizon of 24 months, more than $60 \%$ of the forecast error variance in the buying index is explained by its own innovations. Important determinants of the buying index for houses in descending order of importance include current interest rates, expected interest rates and expected income. Innovations in current income and house prices have an insignificant role in explaining the forecast error variance in the index denoting buying conditions for houses.

Note that the forecast error variance decompositions only give us the proportion of the forecast error variance in the buying index that is explained by its determinants. They do not indicate the direction (positive or negative) or the nature (temporary or permanent) of the variation. Thus, the impulse response analysis is used to analyze the dynamic relationship among variables.

Impulse responses are shown in figures 2-6. The direction of changes observed in the impulse responses conform to the signs obtained earlier in the cointegrating vector. Thus a one standard deviation shock to the current and expected interest rate has a negative short-run and long-run impact on the buying index. The net impact of a one standard deviation shock to the current and future income level is positive in the short- and long-run although there are temporary blips in the responses.

The impact of a rise in house prices is positive in the very short-run although it soon becomes negative. This initial positive impact may be because people expect prices to rise further and therefore are willing to buy houses in the short-run despite a rise in prices. Over time, this effect weakens.

It is noteworthy that all shocks have a permanent effect on the level of buying index, which is what we expect given that it is nonstationary.

\section{Conclusions}

This paper finds that consumers' perceptions of buying conditions for houses are cointegrated with current and expected interest rates, current and expected real disposable income and current prices of homes. This relationship is statistically 
significant and each of the above determinants Granger causes home buying attitudes. The generalized variance decompositions show that of the above determinants of perceptions of buying conditions for houses, current and expected interest rates play the most important role. The direction of the generalized impulse responses conform to the signs obtained in the cointegrating vector. Shocks to each of the determinants have a long-run impact on buying attitudes that is consistent with economic theory.

Since the buying index measures the percentage of respondents saying that it is a "good time" to buy a house relative to the percentage of respondents saying that it is a "bad time", the results of this study suggest that actual purchases of houses are sensitive to both current and future interest rates. Furthermore, the variance decompositions show that expectations of real disposable income are more important than current income in driving purchases of houses. While the price of houses has the correct sign and shocks to it have a permanent, long-run impact on buying intentions, it is relatively less important than interest rates and income in determining consumers' intentions to purchase a house. 


\section{References}

Arnott, R. (1987), "Economic Theory and Housing," Handbook of Regional and Urban Economics, Volume II, Urban Economics, ed. by E.S. Mills, North-Holland Amsterdam (Chapter 24), pp. 959-88.

Baffoe-Bonnie J. (1998), "The Dynamic impact of Macroeconomic Aggregates on Housing Prices and Stock of Houses: A National and Regional Analysis," Journal of Real Estate Finance and Economics, 17, 179-97.

Bram, J. and Sydney Ludvigson (1998), "Does Consumer Confidence Forecast Household Expenditure? A Sentiment Index Horse Race," Federal Reserve Bank of New York, Policy Review, June, 59-78.

Campbell, J. Y. and P. Perron (1991), "Pitfalls and Opportunities: What Macroeconomists Should Know About Unit Roots", NBER Macroeconomic Annual, University of Chicago Press, Illiniois.

Carlson, J. and M. Parkin (1975), "Inflation Expectations," Economica, 42, pp. 123-138.

Carroll, C.D., J.C. Fuhrer and D.W. Wilcox (1994), "Does Consumer Sentiment Forecast Household Spending? If So, Why?" American Economic Review, 84, pp. 1397-1408.

Chen Ming-Chi and K. Patel (1998), "House Price Dynamics and Granger Causality: An Analysis of Taipei New Dwelling Market", Journal of Asian Real Estate Society, Vol. 1 No 1, pp. 101-126.

Curtin, R.T. (1982), "Indicators of Consumer Behavior: The University of Michigan Surveys of Consumers", Public Opinion Quarterly, 46, pp. 340-352.

Dickey, D. A. and W. A. Fuller (1979), "Distribution of the Estimators for Autoregressive Time Series with a Unit Root", Journal of the American Statistical Association, 74, pp. 427-31.

( 1981), "Likelihood Ratio Statistics for Autoregressive Time Series with a Unit Root", Econometrica, 49, pp. 1057-72.

Dolado, J., T. Jenkinson, and S. Sosvilla-Rivero (1990), "Cointegartion and Unit Roots", Journal of Economic Surveys, 4, pp.249-73.

Dua, P. and D.J. Smyth (1995), "Forecasting US Home Sales Using BVAR Models and Survey Data on Households' Buying Attitudes for Homes," Journal of Forecasting, 14, pp. 217-227.

Ewing, Bradley T. and Y. Wang (2002), "Single Housing Starts and Macroeconomic Activity", Working Paper Series 2002-08, Department of Economics, Texas Tech University.

Feldstein, M. S. (1992), "Comment on James M. Poterba's paper: Tax Reform and the Housing Market in the Late 1980s: Who Knew What, and When Did They Know It?". In Lynne Browne and Eric S. Rosegren, eds., Real Estate and Credit Crunch, Federal Reserve Bank of Boston Conference Series, No. 36, 252-57. 
Follain, J. R. (1981), "Does Inflation Affect Real Behavior? The Case of Housing", Southern Economic Journal, 48, 570-82.

Fuhrer, J.C. (1993), "What Role Does Consumer Sentiment Play in the US Macroeconomy?", Federal Reserve Bank of Boston, New England Economic Review, Jan./Feb., pp. 32-44.

Garner, A.C. (1991), "Forecasting Consumer Spending: Should Economists Pay Attention to Consumer Confidence Surveys?", Federal Reserve Bank of Kansas City, Economic Review, May/June, pp. 57-71.

Granger, C. W. J. (1986), "Developments in the Study of Cointegrated Variables", Oxford Bulletin of Economics and Statistics, 48, pp. 213-27.

Granger, C. W. J. (1988) "Some Recent Developments in the Concept of Causality", Journal of Econometrics, 39, 199-212.

Hanushek, E. A. and John M. Quigley (1982), "The Determinants of Housing Demand", in J. V. Henderson eds., Research in Urban Economics, Vol II, JAI Press, 221-42.

Harris, J. (1989), "The Effect of Real Rates of Interest on Housing Prices", Journal of Real Estate Finance and Economics, 2, 47-60.

Johansen, S. and K. Juselius (1990), "Maximum Likelihood Estimation and Inference on Cointegration with Applications to the Demand for Money", Oxford Bulletin of Economics and Statistics, 52, pp. 169-209.

(1992), "Testing Structural Hypothesis in a Multivariate Cointegration Analysis of PPP and the UIP for UK", Journal of Econometrics, 53, pp. 211-44.

Kearl, J. H. (1979), "Inflation, Mortgages and Housing", Journal of Political Economy, 87, 1-29.

Koop, G., M. H. Pesaran, and S. M. Potter (1996), "Impulse Response Analysis in Nonlinear Multivariate Models", Journal of Econometrics, 74, pp. 119-147.

Kwiatkowski, Denis, Peter C.B. Phillips, Peter Schmidt, and Yongcheol Shin (1992), "Testing the Null Hypothesis of Stationarity against the Alternative of a Unit Root", Journal of Econometrics, 54, 159-178.

Leeper, E. (1992), "Consumer Attitudes: King for a Day", Federal Reserve Bank of Atlanta, Economic Review, 77, pp. 1-15.

Lutkepohl, H. (1991), "Introduction to Multiple Time Series Analysis”, Springer-Verlag, New York.

Maclennan, D., Muellbauer, J. and Stephens, M. (1998), "Asymmetries in Housing and Financial Market Institutions and EMU", Oxford Review of Economic Policy, 14, 54-80.

Manchester, J. (1987), "Inflation and Housing Demand: A New Perspective", Journal of Urban Economic Literature, 30, 102-142. 
Matsusaka, J.G. and A.M. Sbordone (1995), "Consumer Confidence and Economic Fluctuations", Economic Inquiry, pp. 296-318.

Megbolugbe, I.F., A.P. Marks and M.B. Schwartz (1991), "The Economic Theory of Housing Demand: A Critical Review", Journal of Real Estate Research, 6, pp. 381-93.

Muellbauer, J. (1992), "Anglo-German Differences in Housing Market Dynamics: The Role of Institutions and Macroeconomic Policy", European Economic Review, Papers and Proceedings, 36, 539-48.

Muellbauer, J. and Murphy, A. (1997), "Booms and Busts in the UK Housing Market", Economic Journal, 107, 1701-27.

Pesaran, M. H. and B. Pesaran (1997), "Working with Microfit 4.0: An Interactive Econometric Software Package (DOS and Windows versions)", Oxford university Press, Oxford.

Pesaran, M. H. and Y. Shin (1998), "Generalized impulse response analysis in linear multivariate models", Economic Letters, 58, 1, pp. 17-29.

Phillips, P. and P. Perron (1988), "Testing for a Unit Root in Time Series Regression", Biometrica, 75, pp. 335-46.

Sims, C. (1980), "Macroeconomics and Reality", Econometrica, 48, pp. 1-48

(1981), "An Autoregressive Index Model for the US 1948-1975", Large Scale Econometric Models, ed. J. B. Ramsey, North-Holland, The Netherlands.

Schwab, R. (1983), "Real and Nominal Interest Rates and the Demand for Housing", Journal of Urban Economics, 13, 181-195.

Schwartz, M.B. (1988), "The Estimation of Housing Demand: A Review of the Research and Its Implications", National Association of Realtors, Forecasting and Policy Analysis Division.

Smith, L.B., K.T. Rosen and G. Fallis (1988), "Recent Developments in Economic Models of Housing Markets", Journal of Economic Literature, 26, pp. 29-64.

Smith, B. A., and W. P. Tesarek (1991), "House Prices and Regional Real Estate Cycles: Market Adjustments in Houston", Journal of American Real Estate and Urban Economics Association, 19, 396-416.

Sternlieb, G. and J. W. Hughes (1977), "Regional Market Variations: The Northeast Versus the South", Journal of American Real Estate and Urban Economics Association (Spring), 44-68.

Throop, A. (1992), "Consumer Sentiment: Its Causes and Effects", Federal Reserve Bank of San Francisco, Economic Review, No. 1, pp. 35-59. 
Table 1: Unit Root Tests (1978:01-2003:06)

\begin{tabular}{|c|c|c|c|}
\hline Variable & ADF Test & PP Test & KPSS \\
\hline \hline $\mathbf{B I}$ & $\mathrm{I}(1)$ & $\mathrm{I}(1)$ & $\mathrm{I}(1)$ \\
\hline $\boldsymbol{I}$ & $\mathrm{I}(1)$ & $\mathrm{I}(1)$ & $\mathrm{I}(1)$ \\
\hline $\boldsymbol{I}$ & $\mathrm{I}(1)$ & $\mathrm{I}(0)$ & $\mathrm{I}(1)$ \\
\hline $\boldsymbol{Y}$ & $\mathrm{I}(1)$ & $\mathrm{I}(1)$ & $\mathrm{I}(1)$ \\
\hline $\mathbf{v}^{\mathbf{e}}$ & $\mathrm{I}(1)$ & $\mathrm{I}(0)$ & $\mathrm{I}(1)$ \\
\hline $\boldsymbol{P}$ & $\mathrm{I}(1)$ & $\mathrm{I}(0)$ & $\mathrm{I}(1)$ \\
\hline
\end{tabular}

Note: For all the tests critical values at $1 \%$ have been used.

Table 2: Tests for Cointegration - Maximum Eigenvalue Test

\begin{tabular}{|c|c|c|c|c|c|}
\hline \multirow{2}{*}{$\mathrm{H}_{0}:$} & \multirow{2}{*}{$H_{A}:$} & \multirow{2}{*}{$\begin{array}{c}\text { Statistic } \\
\mathbf{s}\end{array}$} & \multicolumn{2}{|c|}{ Critical values } & \multirow{2}{*}{ Results } \\
\hline & & & $99 \%$ & $95 \%$ & \\
\hline \multicolumn{6}{|c|}{ MODEL: $\mathrm{BI}=\mathrm{f}\left(i, i^{\mathrm{e}}, y, \mathrm{y}^{\mathrm{e}}, p\right)$} \\
\hline$r=0$ & $r=1$ & 64.81 & 45.10 & 39.37 & Reject Null Hypothesis \\
\hline$r \leq 1$ & $r=2$ & 35.09 & 38.77 & 33.46 & $\begin{array}{c}\text { Do not Reject Null } \\
\text { Hypothesis }\end{array}$ \\
\hline
\end{tabular}

Note: $r$ is the order of cointegration. Critical values are from Osterwald M. and Lenum (1992).

Table 3: Zero-restriction Test of Cointegrating Vector

\begin{tabular}{|c|c|c|}
\hline $\begin{array}{c}\text { Variable } \\
\mathbf{s}\end{array}$ & $\begin{array}{c}\chi^{2} \text { (calculated) } \\
p \text {-value in } \\
\text { parenthesis }\end{array}$ & Conclusion \\
\hline \multicolumn{3}{|c|}{ MODEL : $\mathrm{BI}=\mathrm{f}\left(i, i^{\mathrm{e}}, y, \mathrm{y}^{\mathrm{e}}, p\right)$} \\
\hline i & $35.42(0.00)$ & $\begin{array}{l}\text { Reject null } \\
\text { hypothesis }\end{array}$ \\
\hline$i^{e}$ & $01.61(0.20)$ & $\begin{array}{c}\text { Reject null } \\
\text { hypothesis** }\end{array}$ \\
\hline$y$ & $18.09(0.00)$ & $\begin{array}{l}\text { Reject null } \\
\text { hypothesis }\end{array}$ \\
\hline $\mathbf{y}^{\mathbf{e}}$ & $03.21(0.07)$ & $\begin{array}{l}\text { Reject null } \\
\text { hypothesis* }\end{array}$ \\
\hline$p$ & $25.25(0.00)$ & $\begin{array}{l}\text { Reject null } \\
\text { hypothesis }\end{array}$ \\
\hline
\end{tabular}

${ }^{*}$ and ${ }^{* *}$ denote $10 \%$ and $20 \%$ level of significance respectively. 


\section{Table 4: Granger Causality Tests}

\begin{tabular}{|c|c|c|c|}
\hline Null Hypothesis & $\begin{array}{c}\text { Number of } \\
\text { Lags }\end{array}$ & $\begin{array}{c}\chi^{2} \text { (calculated) } \\
\text { p-value in } \\
\text { parenthesis }\end{array}$ & Conclusion \\
\hline \multicolumn{4}{|l|}{ MODEL: $\mathrm{BI}=\mathrm{f}\left(i, i^{\mathrm{e}}, y, \mathrm{y}^{\mathrm{e}}, p\right)$} \\
\hline $\mathrm{BI}$ is not granger caused by $i$ & 3 & $19.95(0.00)$ & $\begin{array}{l}\text { Reject null } \\
\text { hypothesis }\end{array}$ \\
\hline $\mathrm{BI}$ is not granger caused by $\mathbf{P}$ & 3 & $30.37(0.00)$ & $\begin{array}{l}\text { Reject null } \\
\text { hypothesis }\end{array}$ \\
\hline $\mathrm{BI}$ is not granger caused by $\boldsymbol{y}$ & 3 & $13.31(0.01)$ & $\begin{array}{l}\text { Reject null } \\
\text { hypothesis }\end{array}$ \\
\hline $\mathbf{B I}$ is not granger caused by $\mathbf{y}^{\mathbf{e}}$ & 3 & $17.27(0.01)$ & $\begin{array}{l}\text { Reject null } \\
\text { hypothesis }\end{array}$ \\
\hline $\mathbf{B I}$ is not granger caused by $\boldsymbol{p}$ & 3 & $21.20(0.00)$ & $\begin{array}{l}\text { Reject null } \\
\text { hypothesis }\end{array}$ \\
\hline
\end{tabular}

Table 5: Generalized Forecast Error Variance Decompositions for Variable BI

\begin{tabular}{|c|c|c|c|c|c|c|}
\hline $\begin{array}{c}\text { Horizon } \\
\text { (Months) }\end{array}$ & $\mathbf{B I}$ & $\boldsymbol{i}$ & $\boldsymbol{i}^{\mathbf{e}}$ & $\boldsymbol{y}$ & $\boldsymbol{y}^{\mathbf{e}}$ & $\boldsymbol{p}$ \\
\hline $\mathbf{1}$ & 0.917 & 0.114 & 0.053 & 0.001 & 0.039 & 0.004 \\
\hline $\mathbf{4}$ & 0.725 & 0.269 & 0.160 & 0.008 & 0.080 & 0.007 \\
\hline $\mathbf{6}$ & 0.663 & 0.302 & 0.194 & 0.007 & 0.092 & 0.021 \\
\hline $\mathbf{1 2}$ & 0.624 & 0.325 & 0.226 & 0.006 & 0.103 & 0.025 \\
\hline $\mathbf{1 8}$ & 0.615 & 0.337 & 0.235 & 0.006 & 0.105 & 0.022 \\
\hline $\mathbf{2 4}$ & 0.609 & 0.342 & 0.241 & 0.006 & 0.107 & 0.022 \\
\hline
\end{tabular}

Note: Entries in each row are the percentages of the variances of the forecast error in the buying index that can be attributed to each of the variables indicated in the column headings. The decompositions are reported for one-, four-, six-, twelve-, and twenty four-month horizons. The extent to which the generalized error variance decompositions add up to more or less than 100 percent depends on the strength of the covariances between the different errors. 
Figure 1

Index of House Buying Attitudes

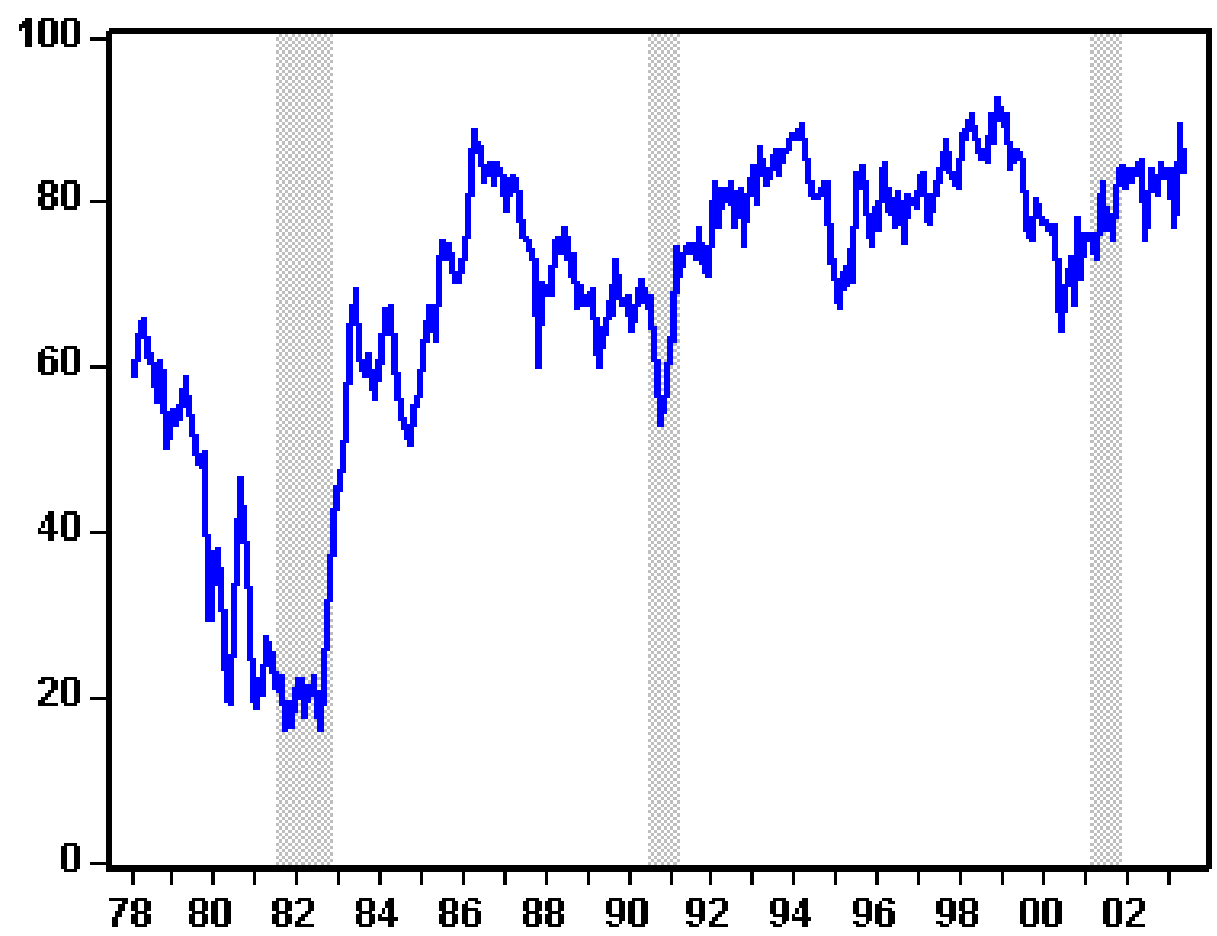

Note: Shaded areas represent U.S. business cycle recessions. 
Generalized Impulse Responses of Buying Index to One Standard Error Shocks to other Variables:

Figure 2: Shock to interest rate (i)

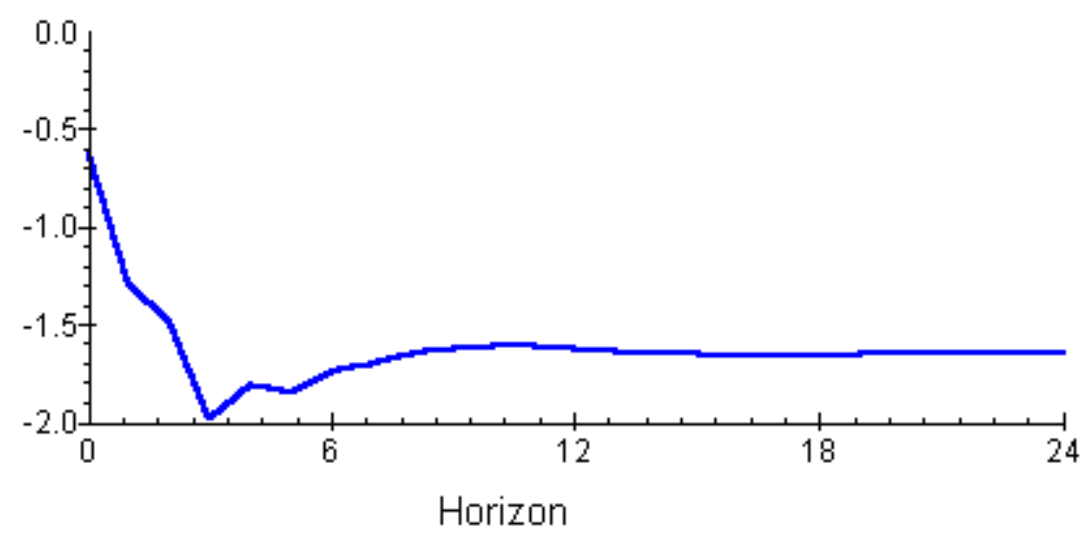

Figure 3: Shock to index of interest rate expectations $\left(i^{\mathrm{e}}\right)$

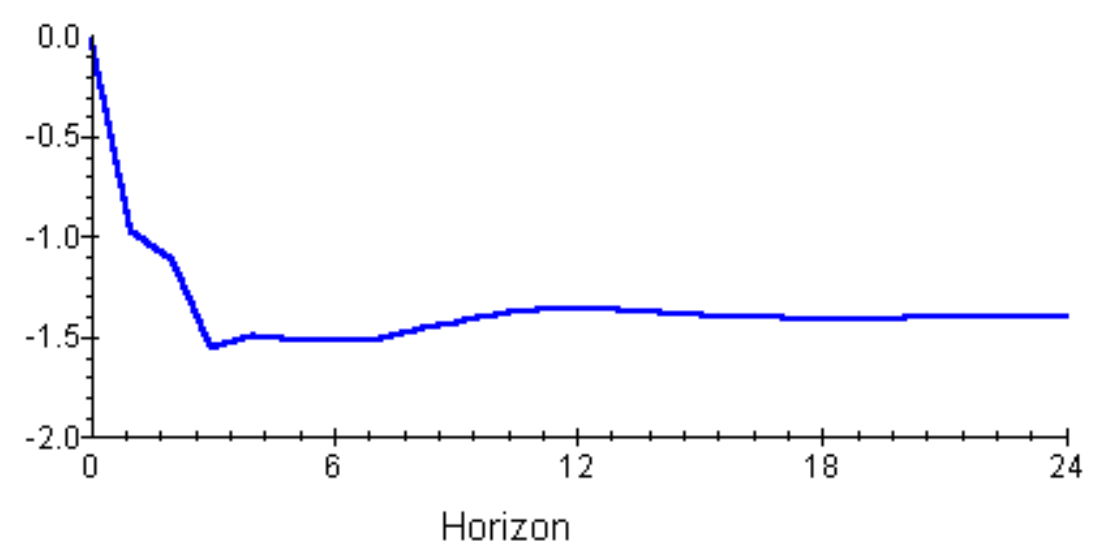

Figure 4: Shock to real disposable income $(y)$

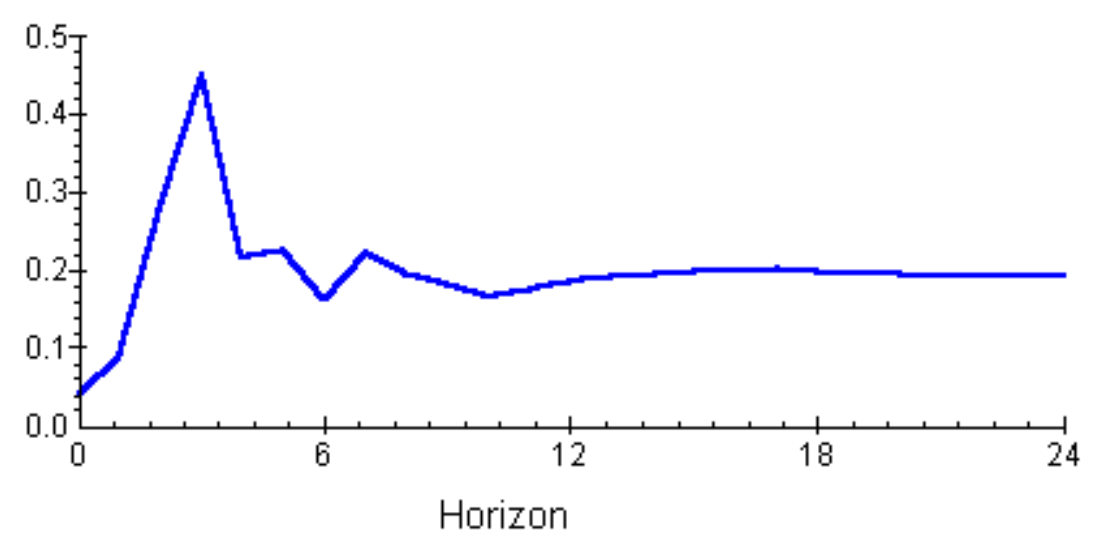


Figure 5: Shock to index of real family income expectations $\left(y^{e}\right)$

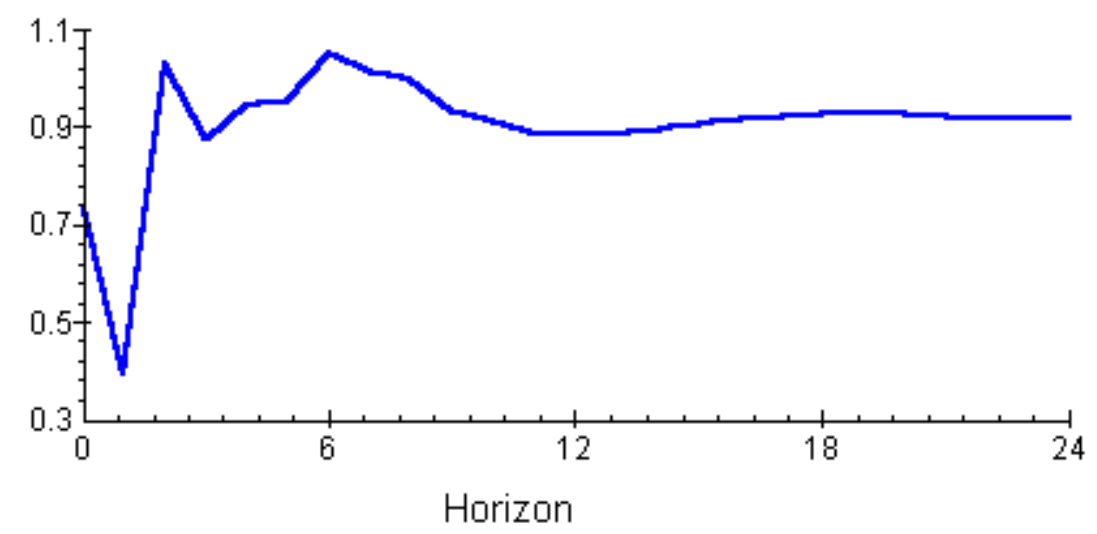

Figure 6: Shock to house prices (p)

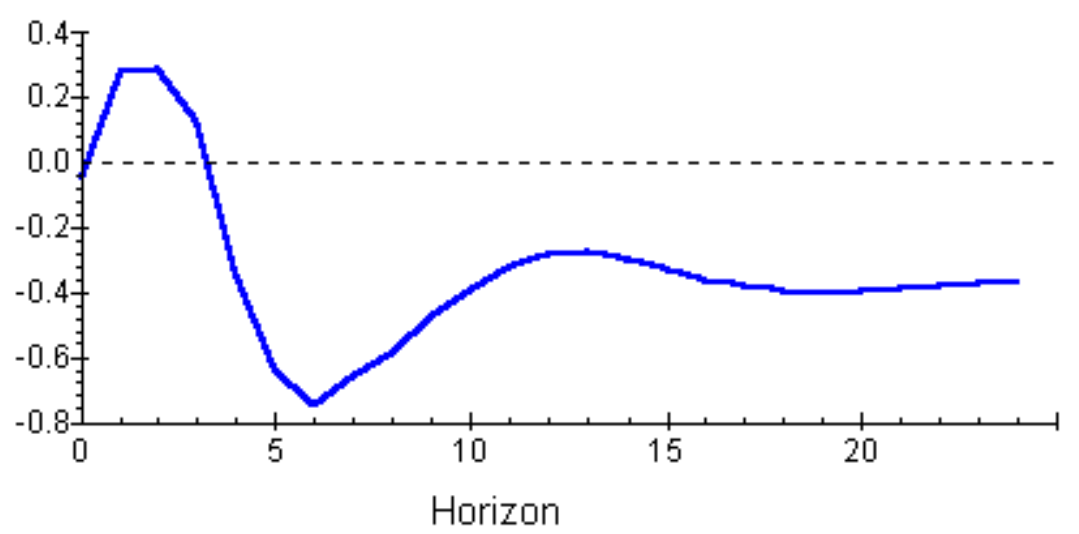

* Complete list of working papers is available at the CDE website: http://www.cdedse.org/worklist.pdf 